\title{
Letter
}

\section{On Fructosazone Regiochemistry}

\section{Francisco Sánchez-Viesca*, Reina Gómez}

Organic Chemistry Department, Faculty of Chemistry, National Autonomous University of Mexico, Mexico City, México

\section{Email address:}

franviesca@yahoo.com (F. Sánchez-Viesca), reinagomezg@yahoo.com.mx (R. Gómez)

\section{To cite this article:}

Francisco Sánchez-Viesca, Reina Gómez. On Fructosazone Regiochemistry. Modern Chemistry. Vol. 4, No. 1, 2016 , pp. 1-5. doi: $10.11648 /$ j.mc.20160401.11

\begin{abstract}
The regiochemistry observed in fructosazone has not been explained by other authors. A novel reaction mechanism has been provided in order to explain the regioselectivity leading to the fructosazone molecule. Our proposal and subsequent reactions are in agreement with the experimental facts and with well known reactivities. So, we have eliminated the existing gap between fact and theory. Many years have elapsed before an answer was given at last.
\end{abstract}

Keywords: Fructosazone, Reaction Mechanisms, Reaction Intermediates, Regioselectivity, Retro-Amadori Rearrangement

\section{Introduction}

There are several studies on the mechanism of osazone formation, and are commented in the next section.

In glucose, with a terminal carbonyl group, there is no reaction alternative in order to form a vicinal bis-phenyl hydrazone. The osazone is formed at C-1 and C-2. In fructose, the carbonyl group at $\mathrm{C}-2$ could give a vicinal bis-phenyl-hydrazone at $\mathrm{C}-1, \mathrm{C}-2$ or at $\mathrm{C}-2, \mathrm{C}-3$. However, there is further reaction only at $\mathrm{C}-1$, giving the same osazone that is obtained with glucose. This regioselectivity has not been explained by other authors. We presented a short communicationon the theme [1]. In this extended work we deal in addition with the last steps of osazone formation since they are in accordance with the intermediate arising from our proposals, as we will see.

\section{Experimental Facts and Theories}

In glucosazone formation, there is an oxidation of the hydroxymethylene group adjacent to the first obtained phenylhydrazone. Then, the second phenylhydrazone can be formed. It was considered that the oxidation of the involved secondary alcohol was performed by a phenylhydrazine molecule, since three molecules of this reagent are required. This point of view was discarded because phenylhydrazine has not oxidizing properties [2].

In order to explain glucosazone formation, two alternative routes, A and B, were proposed by F. Weygand [3, 4]. They have been pointed out $[5,6]$ and will be commented later.

The oxidation step proposed by Weygand, which is common to both routes, is of interest to us because it does not explain the regioselectivity observed in fructosazone. He considers that in glucosazone formation there is an internal oxido-reduction that can be explained involving an Amadori rearrangement, i.e., the isomerization of the N-glycoside of an aldose (glycosylamine) to the corresponding 1-amino-1-deoxy-ketose [7-9] (Figure 1).<smiles>[R]C(O)C=O</smiles>

aldose

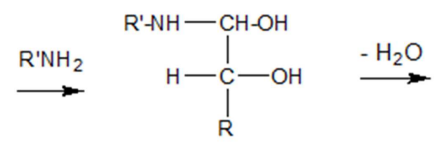

1,1-aminoalcohol
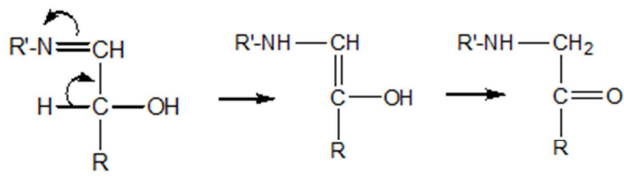

aminoglycoside or glycosylamine (open form as Schiff base)

Figure 1. Amadori rearrangement.

In osazone formation, the phenylhydrazone of the aldol is formed. This intermediate isomerizes to a hydroxy-aminoethylene analog. Then, this enol originates the isoglycosylamine, as is shown in Figure 2. 
<smiles>[R]C(=O)CNNc1ccccc1</smiles>

Figure 2. Proposed Amadori rearrangement in osazone formation.

A similar isomerization is the retro-Amadori or Heyns rearrangement $[7,10,11]$. In this reaction, a ketosylamine (glycosylamine) is transformed to the corresponding 2-amino-2-deoxy-aldose (Figure 3).<smiles>CC(=O)OC(=O)CO</smiles>

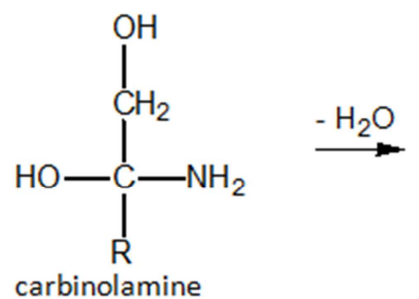<smiles>[R]C(=N)C(O)O</smiles><smiles>[R]/C(N)=C/O</smiles><smiles>[R]C(N)(C=O)CC</smiles>

$$
\begin{array}{cc}
\text { glycosylamine } & \text { 2-amino-2-deoxy } \\
\text { (open form) } & \text { aldose }
\end{array}
$$

Figure 3. Heyns Rearrangement.

Heyns isomerized the intermediate D-fructosylamine, not isolated, into 2-amino-2-deoxy-D-glucose (D-glucosamine), employing $10 \% \mathrm{NH}_{4} \mathrm{OH}[10]$, as well as liquid ammonia [11].

A year later, J. F. Carson [12], in California, employed anhydrous isopropyl - and cyclohexylamine, instead of ammonia, and obtained the amines resulting from the rearrangement. These reactions were carried at $0^{\circ} \mathrm{C}$ and without a catalyst. The same author [13] isolated in crystalline form the intermediate $\mathrm{D}$-fructosylethylamine. The reaction was carried on at $-20^{\circ} \mathrm{C}$, with a $75 \%$ yield. This compound, in methanol and at room temperature, isomerizes to the stable 2-ethylamino-2-deoxy- $\alpha$-D-glucose, albeit in low yield, and formation of resinous material.

Now we will turn our attention to the next steps in osazone formation. In the reaction of a carbohydrate with phenyl hydrazine, the corresponding phenylhydrazone is formed. As it was mentioned, Weygand [3] proposed two routes, A and B, in order to explain osazone formation in carbohydrates. In route A, glucose phenylhydrazone isomerizes to an enolhydrazine. In the next step, an imino ketone results, with loss of aniline. Finally, the ketimine reacts with two phenyl-hydrazine molecules, with elimination of ammonia (Figure 4).<smiles>[R]/C(O)=C/NNc1ccccc1</smiles>

$$
\text { from aldose enolhydrazine }
$$<smiles>[R]C(=O)/C=N\N(N)C(=O)NNc1ccccc1</smiles>

iminoketone

or ketimine

osazone

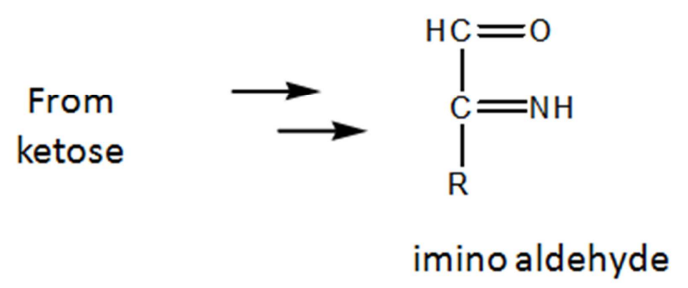

Figure 4. Weygand's route A.

The split of aniline from a ketose phenylhydrazone has been explained [14] as follows, Figure 5.

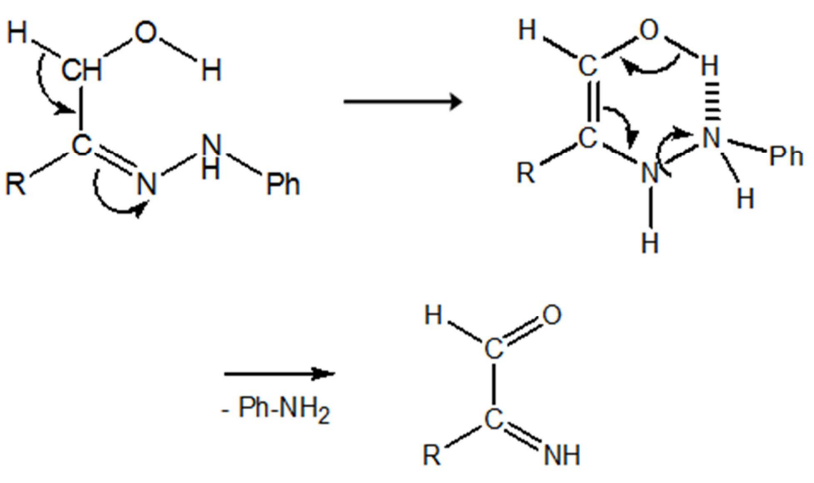

Figure 5. Suggested elimination of aniline.

However, this point of view is dubious due to the low basicity of the $\alpha$-nitrogen because it is stabilized by resonance with the phenyl group. It reacts only with strong acids.

In Weygand's route B, only a ketone is formed from the enolhydrazine. Then, a hydrazinohydrazone is obtained. This intermediate isomerizes to an ene-bis-hydrazine which, by loss of aniline, via a 1, 4-elimination (vinilogous elimination), gives two isomeric iminohydrazones. Finally, reaction with phenylhydrazine forms the osazone, via elimination of ammonia (Figure 6).

There is experimental evidence in favour of both routes, as we will see.

In other communication, Weygand and Reckhaus [4] studied the reaction of the p-nitrophenylhydrazone of a symmetrical $\alpha$-ketol (acyloin) with phenylhydrazine, in order 
to study to which route it is in accord. In both routes, A and B, the first formed $\mathrm{p}$-nitrophenyl-hydrazone turns to the enolic form. Then, in route $\mathrm{A}$, there is ketone formation with simultaneous elimination of p-nitroaniline; whereas in route $\mathrm{B}$ there is only ketone formation, without elimination of p-nitroaniline. Further reactions with added phenylhydrazine give a mixed osazone and also the bis-phenylhydrazone. This is due to the asymmetrical ene-bis-hydrazine formed. The researchers obtained phenyl-p-nitrophenylosazone, which is in accordance with route $\mathrm{B}$.

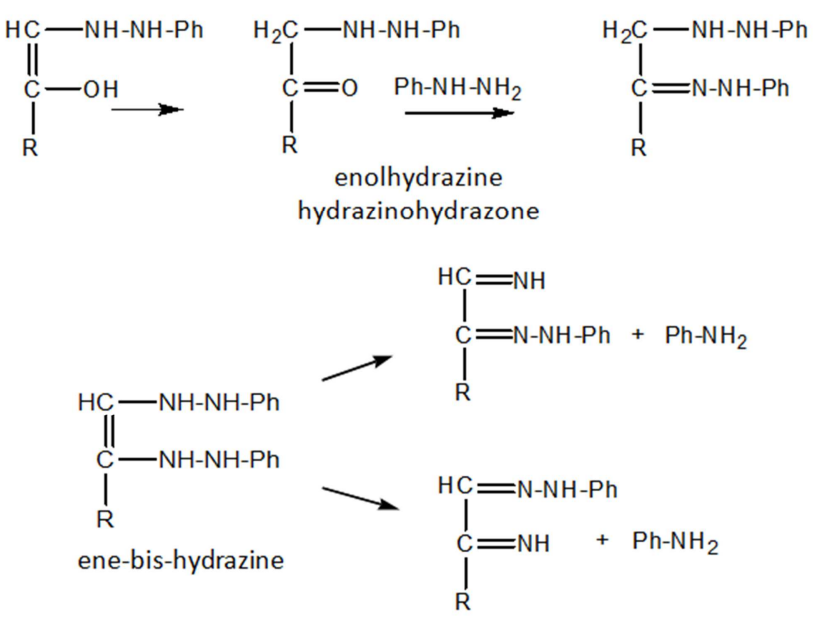

Figure 6. Weygand's route $B$.

In a short communication Barry and Mitchell [15] emphasized that $\beta$-alkyl substituted phenylhydrazines and $\beta$-acetonylphenylhydrazine are oxidized very readily in air to form phenylhydrazones. Thus, the participation of other oxidant could be unnecessary for the oxidation of the $\alpha$-phenylhydrazino ketone, resulting from the Amadori rearrangement, to the corresponding osone. The last one forms the osazone (Figure 7).<smiles>[R]C(=O)CNNc1ccccc1</smiles>

keto hydrazine
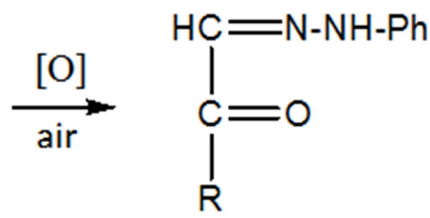

osone
Figure 7. Supposed air oxidation.

This point of view is untenable since, to form an osazone, three molecules of phenylhydrazine are required. The authors point out that would be two hydrogen-acceptors: aerial oxygen and phenylhydrazine. However, it is well known that phenylhydrazine is not an oxidant.

In a reaction mechanism for osazone formation, proposed by Simon and co-workers [16], the glycosylphenylhydrazine is opened by a $\mathrm{C}-\mathrm{H}$ electron pair from the $\mathrm{CH}_{2}-\mathrm{OH}$ group (Figure 8).<smiles>[R]C(=N)C(=O)CC</smiles>

Figure 8. Unacceptable proposed reaction mechanism.

This reactivity is not reasonable, since these hydrogens are not acidic at all and the opening occurs by participation of the vicinal nitrogen electron pair.

Wright [17], studied the reaction of D-mannose phenyl-hydrazone with p-bromophenylhydrazine. The resulting intermediate splits out $\mathrm{p}$-bromoaniline and aniline, in agreement with Weygand's route B, i.e., the existence of a mixed ene-bis-hydrazine as intermediate.

A different study was performed by Shemyakin and co-workers [18, 19], with the use of ${ }^{15} \mathrm{~N}$. The $\beta-{ }^{15} \mathrm{~N}$-p-nitro-phenylhydrazones of various $\alpha$-hydroxy ketones, namely benzoin, cyclohexanolone and $\mathrm{D}$-fructose were selected for investigation. The labelled arylhydrazone was converted to the osazone with unlabelled arylhydrazine, in boiling iso-amyl alcohol or in glacial acetic acid at $50^{\circ} \mathrm{C}$ (Figure 9).<smiles>[R]C(CO)=[N+](NS)[NH+](C)O</smiles>
arylhydrazone<smiles>CC(=[NH2+])C=O</smiles>
$+\mathrm{NH}_{2}-\mathrm{Ph}-\mathrm{NO}_{2}$

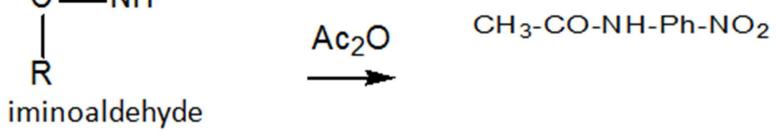<smiles>CC(C)(C)[PbH]NN</smiles><smiles>[R]C(=[NH2+])/C=N\Nc1ccccc1</smiles>

iminohydrazone<smiles></smiles>
enolhydrazine<smiles>[R]C(/C=N\Nc1ccccc1)=N/[NH3+]</smiles>

osazone
Figure 9. Shemyakin's experiment is in accordance with Weygand's route A with a ketose: ${ }^{15} N=N^{*}$.

Heating of D-fructose- $\beta-{ }^{15} \mathrm{~N}$-p-nitrophenylhydrazone and ordinary phenylhydrazine in acetic acid in the presence of acetic anhydride leads to the formation in quantitative yield of unlabelled p-nitroacetanilide and ammonia containing almost the entire initial ${ }^{15} \mathrm{~N}$. These results are in accordance with Weygand's route A: an aldimine is formed after p-nitro-aniline splitting, and finally, labelled $\mathrm{NH}_{3}$ is obtained. 


\section{Discussion}

Fructose gives an osazone at $\mathrm{C}-1, \mathrm{C}-2$. But, being the carbonyl group at $\mathrm{C}-2$, why an osazone at $\mathrm{C}-2, \mathrm{C}-3$ is not formed? This regioselectivity not only has not been explained, it has been overlooked.

We provide a reaction mechanism that explains the observed regiochemistry. Our proposal is based in very well known reactivities and in related reactions, as we will see.

It is established that the reaction of an $\alpha$-hydroxycarbonyl compound (an $\alpha$-ketol) and an arylhydrazine gives the aryl-hydrazone. The problem is why, in fructosazone formation (a variant of the Heyns rearrangement), the reaction proceeds to $\mathrm{C}-1$ and not to $\mathrm{C}-3$. At this step, the only existing difference is that at $\mathrm{C}-1$ there is a primary alcohol, and at C-3 there is a secondary one. Their respective reactivities are: in acidic medium, the secondary alcohol can be dehydrated more easily than a primary one; but, in the presence of a base, a primary alcohol is more reactive than a secondary one $[20,21]$. Thus, the greater acidity of the primary alcohol in the hydroxymethyl group (C-1), must be the determinant factor in the next step. Both hydroxy groups, at $\mathrm{C}-1$ and at $\mathrm{C}-3$, can form a hydrogen bond with the arylhydrazone $\beta$-nitrogen. However, from these two possibilities, the hydrogen bond with the primary alcohol at $\mathrm{C}-1$ is preferred because this $\mathrm{OH}$ is a better hydrogen donor due to its greater acidity (Figure 10).
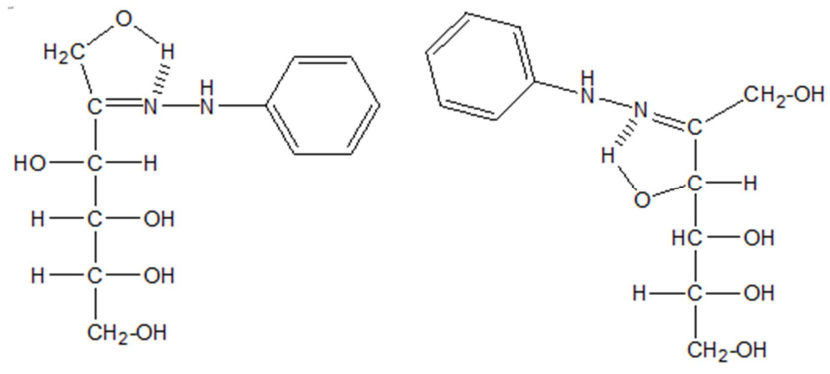

Figure 10. Two possibilities of hydrogen bond formation in fructose phenylhydrazone. The first is the preferred one.

It is well known that nitrogen can react as an organic base (a Lewis base); so, besides forming a five member secondary ring, it can promote an internal oxido-reduction, via a cyclic concerted-mechanism (internal catalysis) Figure 11.

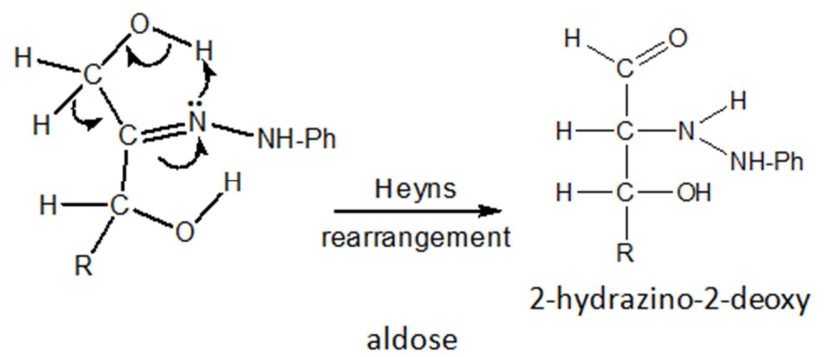

Figure 11. Concerted oxido-reduction step in fructose phenylhydrazone.

The required driving force can be coming from the hot solvent (thermal rearrangement). Cf. Shemyakin [18, 19]. This experimental fact supports our theory that no catalyst intervene in this step of osazone formation. The autocatalysis is independent of an external medium (when $\mathrm{AcOH}$ is used) because internal factors are immediate and predominate over external ones.

In our case the five-member ring is preferred to a six-member one because the $\mathrm{C}=\mathrm{N}$ group yields to the $\beta$-nitrogen in the phenylhydrazone a $\delta^{-}$charge, and this is not present in the $\alpha$-nitrogen. On the contrary, there is a $\delta^{+}$in the $\alpha$-nitrogen. In molecular-orbital theory, the unshared electron pair in this nitrogen is in a p-orbital that overlaps with the benzene $\pi$-orbital system, thus lowering the nitrogen basicity. According to valence-bond formulation, the electron pair on this nitrogen is distributed over the aromatic ring and thus is less available. Besides, a six-member ring does not favour a concerted reaction mechanism.

Examples of 1, 2-alkyl migration, with concomitant 1, 4-hydrogen transfer, have been reported in $\alpha$-hydroxy imines [22] Figure 12. These reactions, although different, are in line with the proposed reaction mechanism.

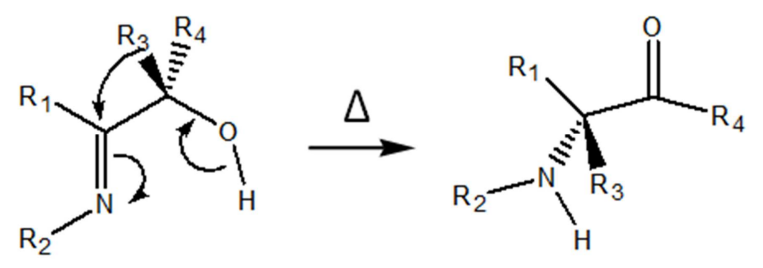

Figure 12. Thermal rearrangement of $\alpha$-hydroxy imines.

The following reactions in fructosazone formation are in Figure 13.

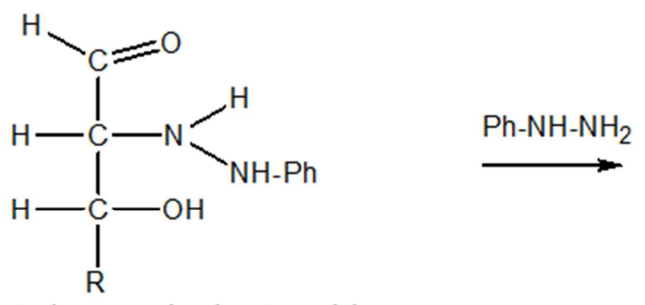

2-deoxy-2-hydrazino aldose

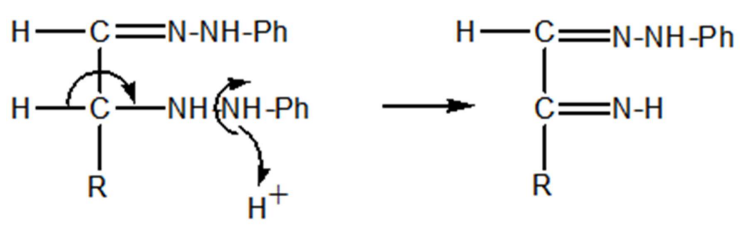

Figure 13. Fructosazone formation, last steps.

The resulting 2-deoxy-2-phenylhydrazino-D-glucose forms the corresponding phenylhydrazone. The last compound split out aniline, giving an $\alpha$-imino phenyl-hydrazone. This intermediate is in accord with Shemyakin's experiments [18, 19]. Reaction with other phenylhydrazine molecule leads to an aminal. Finally, loss of ammonia gives the osazone.

Thus, we have cleared the regioselectivity in fructosazone formation. Our proposal and subsequent reactions are entirely in accord with the experimental facts and with well known 
reactivities.

\section{Conclusion}

In order to explain the regiochemistry observed in fructosazone, several factors were invoked in the oxido-reduction step, instead of simple prototropy, as it was believed formerly.

Different reactivities are in play in the disproportionation of the phenylhydrazone, such as the acidity of the primary and secondary alcohols, selective hydrogen bond formation and a hydrogen transfer, via a concerted five-member reaction-mechanism. This process explains the regiochemistry observed in fructosazone. This theme had eluded explanation for too many years.

\section{References}

[1] F. Sánchez-Viesca, and R. Gómez, "On the regiochemistry in the Heyns rearrangement", Am. J. Chem., vol. 5(3), pp. 86-89, 2015. DOI: $10.5923 /$ j.chemistry.20150503.03

[2] J. Packer, and J. Vaughan, A Modern Approach to Organic Chemistry, Oxford, U. K.: Clarendon Press, 1958, pp. 479-482.

[3] F. Weygand, "Theorie der Osazonbildung", Ber., vol. 73(11), pp. 1284-1291, 1940; Chem Abstr., vol. 35, 3235, 1941.

[4] F. Weygand, and M. Reckhaus, "Zur Theorie der Osazonbildung”, Chem. Ber., vol. 82(4-5), pp. 438-442, 1949; Chem. Abstr., vol. 44, 1911-1912, 1950.

[5] E. G. V. Percival, "The structure and reactivity of the hydrazone and osazone derivatives of the sugars", Adv. Carbohydr. Chem., vol. 3, pp. 23-44, 1948.

[6] A. Hassner, and P. Catsoulacos, "On the mechanism of osazone formation”, Tetrahedron Lett. No. 6, pp. 489-493, 1967.

[7] T. M. Wrodnigg, and B. Eder, "The Amadori and Heyns rearrangements", Top. Curr. Chem., vol. 215, pp. 115-152, 2001.

[8] F. Weygand, “Amadori Umlagerungen”, Ber., vol. 73(11), pp. 1259-1278, 1940; Chem. Abstr., vol. 35, 3234-3235, 1941.

[9] H. S. Isbell, and H. L. Frush, "Mutarotation, hydrolysis, and rearrangement reactions of glycosylamines", J- Org. Chem., vol. 23(9), pp. 1309-1319, 1958.

[10] K. Heyns, and W. Koch, "Formation of an amino sugar from D-fructose and ammonia", Z. Naturforsch., vol. 7b, pp. 486-488, 1952; Chem. Abstr., vol. 47, 3392f, 1953.

[11] K. Heyns, and K. H. Meinecke, "Über Bildung und Darstellumg von d-Glucosamin aus Fructose und Ammoniak", Chem. Ber., vol. 86(11), pp. 1453-1462, 1953; Chem. Abstr., vol. 49, 2333d, 1955.

[12] J. F. Carson, "The reaction of fructose with isopropylamine and cyclohexylamine", J. Am. Chem. Soc., vol. 77, pp. 1881-1884, 1955.

[13] J. F. Carson, "The reaction of fructose with aliphatic amines", J. Am. Chem. Soc., vol. 77, pp. 5957-5960, 1955.

[14] B. Metha, and M. Metha, Organic Chemistry, Prentice-Hall of India, 2005, p. 939.

[15] V. C. Barry, and E. W. D. Mitchell, "Mechanism of osazone formation", Nature (London), vol. 175, p. 220, 1955.

[16] H. Simon, H. D. Dorrer, and A. Trebst, "Untersuchungen über den Mechanismus der Osazonbildung in der Zuckerreihe", Chem. Ber., vol. 96, pp. 1285-1288, 1963; Chem. Abtr., vol 59, $2918 \mathrm{~g}, 1963$.

[17] C. Sears, and J. C. Wright, "The use of p-bromophenyl-hydrazine to determine the mechanism of osazone formation", Proc. West Virginia Acad. Sci., vol 33, pp. 78-80, 1961; Chem. Abstr., vol. 56, 10254g, 1962.

[18] E. M. Bamdas, K. M. Ermolaev, V. J. Maimind, and M. M. Shemyakin, "Mechanism of osazone formation", Chem. \& Ind. (London), 1959, pp. 1195-1196.

[19] M. M. Shemyakin, V. J. Maimind, K. M. Ermolaev, and E. M. Bamdas, "The mechanism of osazone formation", Tetrahedron, vol. 21, pp. 2771-2777, 1965.

[20] J. McMurry, Química Orgánica, 8th. ed., México: Cengage Learning, 2012, Apéndice B, Constantes de acidez, p. A-9.

[21] V. Migrdichian, Organic Synthesis, New York: Reinhold, 1960, vol 1, p. 16

[22] Ph. Compain, J. Gore, and J. M. Vatele, "Rearrangement of $\alpha$-hydroxy imines to $\alpha$-amino ketones: Mechanistic aspects and synthetic applications", Tetrahedron, vol. 52(19), pp. 6647-6664, 1996 